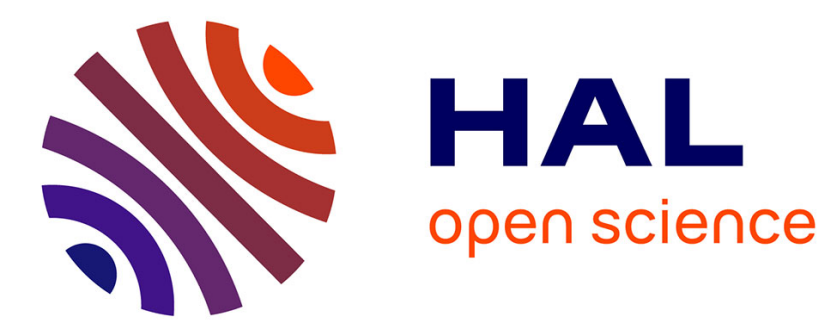

\title{
Knowledge-based modelling applied to synucleinopathies
}

Bernard Kamsu-Foguem, Pierre Tiako, Edward Mutafungwa, Clovis Foguem

\section{To cite this version:}

Bernard Kamsu-Foguem, Pierre Tiako, Edward Mutafungwa, Clovis Foguem. Knowledge-based modelling applied to synucleinopathies. European Geriatric Medicine, 2015, 6 ( $\mathrm{n}^{\circ}$ 6), pp. 381-388. 10.1016/j.eurger.2015.02.011 . hal-01212095

\section{HAL Id: hal-01212095 \\ https://hal.science/hal-01212095}

Submitted on 6 Oct 2015

HAL is a multi-disciplinary open access archive for the deposit and dissemination of scientific research documents, whether they are published or not. The documents may come from teaching and research institutions in France or abroad, or from public or private research centers.
L'archive ouverte pluridisciplinaire HAL, est destinée au dépôt et à la diffusion de documents scientifiques de niveau recherche, publiés ou non, émanant des établissements d'enseignement et de recherche français ou étrangers, des laboratoires publics ou privés. 


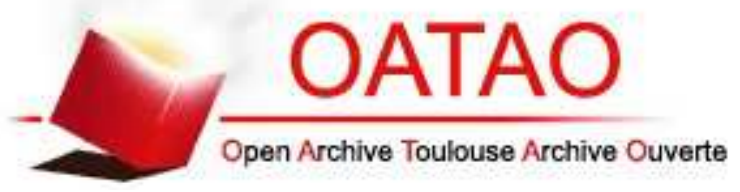

\section{Open Archive Toulouse Archive Ouverte (OATAO)}

OATAO is an open access repository that collects the work of Toulouse researchers and makes it freely available over the web where possible.

This is an author-deposited version published in: http://oatao.univ-toulouse.fr/ Eprints ID: 14090

To link to this article: DOI:10.1016/j.eurger.2015.02.011 http://dx.doi.org/10.1016/j.eurger.2015.02.011

\section{To cite this version:}

Kamsu-Foguem, Bernard and Tiako, Pierre and Mutafungwa, Edward and Foguem, Clovis Knowledge-based modelling applied to synucleinopathies. European Geriatric Medicine. ISSN $\underline{1878-7649}$ 
Technology applied to geriatric medicine

\title{
Knowledge-based modelling applied to synucleinopathies
}

\author{
B. Kamsu-Foguem ${ }^{\text {a,* }}$, P.F. Tiako ${ }^{\text {b }}$, E. Mutafungwa ${ }^{c}$, C. Foguem $^{\mathrm{d}}$ \\ ${ }^{a}$ Laboratory of Production Engineering (LGP), EA 1905, ENIT-INPT, University of Toulouse, 47, avenue d'Azereix, BP 1629,65016 Tarbes cedex, France \\ ${ }^{\mathrm{b}}$ Center for IT Research, Langston University, OK 73050, USA \\ ${ }^{\mathrm{c}}$ Aalto University School of Electrical Engineering, PL 13000, 00076 Aalto, Espoo, Finland \\ ${ }^{\mathrm{d}}$ Center for Food and Taste sciences (CSGA) - UMR 6265 CNRS - UMR 1324 INRA - University of Burgundy, 9E, boulevard Jeanne-d'Arc, 21000 Dijon, France
}

Keywords:

Telemedicine

Ontological knowledge

Collaboration

Semantic modelling

Geriatrics

\begin{abstract}
A B S T R A C T
The adoption of telemedicine technologies has enabled collaborative programs involving a variety of links among distributed medical structures and health officials and professionals. The use for telemedicine for transmission of medical data and the possibility for several distant physicians to share their knowledge on given medical cases provides clear benefits, but also raises several unsolved conceptual and technical challenges. The seamless exchange and access of medical information between medical structures, health professionals, and patients is a prerequisite for the harmonious development of this new medical practice. This paper proposes a new approach of semantic interoperability for enabling mutual understanding of terminologies and concepts used. The proposed semantic interoperability approach is based on conceptual graph to support collaborative activities by describing how different health specialists can apply appropriate strategies to eliminate differential medical diagnosis. Intelligent analysis strategies are used to narrow down and pinpoint medical disorders. The model proposed is fully verified by a case study in the context of elderly patients and specifically dealing with synucleinopathies, a group of neurodegenerative diseases that include Parkinson's disease (PD), dementia with Lewy bodies (DLB), pure autonomic failure (PAF) and multiple system atrophy (MSA).
\end{abstract}

\section{Introduction}

The current medical demography and its uneven distribution, particularly in some medical disciplines, are creating significant challenges in ensuring continuity of care. This has resulted in a pressing need for medical facilities in places where the shortage of specialists is acute. Telemedicine is a tool that enables equal access to medical expertise regardless of place of care [1]. This practice allows physicians of regional institutions to ensure access to competence for different medical investigations or cases and to benefit from the expertise of their colleagues from different specializations (radiology, surgery, psychiatry or neurology) [2]. Indeed, telemedicine has allowed doctors hospitals and clinics to have a network for accessing remote resources and complementary skills [3]. Other benefits of telemedicine include patients who are less tired and stressed and families who no longer have to travel long distances to visit their doctors [4]. Medical practitioners now have in their offices or in their local hospitals capacity identical to those at major hospitals. These advances are potential safeguard measures to ensure the protection of some local

\footnotetext{
* Corresponding author. Tel.: +33 6243023 37; fax: +33 562442708 .

E-mail address: Bernard.Kamsu-Foguem@enit.fr (B. Kamsu-Foguem).
}

hospitals. In summary, telemedicine provides impact in three key dimensions [5]:

- medical impact through improved medical diagnosis and treatment, as well as, the increased competence of practitioners participating in the network;

- territorial impact by maintaining skills and specialized services in hospitals and clinics in medium and smaller cities, especially in rural areas;

- medico-economic impact through reduction in the number of unnecessary transfers and the increase in the number of vital transfers with a useful gain for patients while controlling costs.

The era of technological networks in medicine is inevitable to improve the quality, safety, and continuity of care, while promoting equal access to high quality local care by promoting coordination and cooperation of all stakeholders. At the technological level, further progress can be made in the field of telemedicine if the main obstacles are overcome [6]. By deploying this technology in all remote hospitals or care centers, one improves connectivity by setting application of quality standards and building a relationship of trust. Telemedicine efficiency should allow equitable management of patients. It allows sharing of 
quality image viewing stations (adapted diagnostic), flexible usage of resources (possibility of Web access), and, to ensure that the benefits of such telemedicine can be mutual, provides opportunities for technology transfer and improved efficiency in the healthcare sectors of partners institutions. The development of telemedicine is based on strengthening our innovation capabilities and requires sustained cooperation that cuts across the fields of health, industry, research, and defence [7]. A tele-consultation session can show the various documents available: image of a patient or physician, radiographic images, and other clinical data. In some circumstances, remote biotechnology tools can be used to perform enriched diagnostics by molecular techniques, targeting of pathogens, and identification of sensitivities to drugs in order to enhance treatment [8].

The rest of the paper is structured as follows. Section 2 exposes the material and methods with the conceptual graph operations used to implement the modelling of expert rules in collaborative decision-making processes. Section 3 presents the results with an illustrative case for the telemedicine management within the geriatrics field is presented. Finally, section 4 provides a discussion and section 5 concludes and discusses lessons learned and future challenges.

\section{Material and methods}

\subsection{Knowledge formalization with conceptual graphs}

The conceptual graph (CG) formalism is a knowledge representation language, which has a well-defined syntax and a formal semantics that allows one to reason from its representations [9]. The conceptual graph formalism is considered as a compromise representation between a formal language and a graphical language, because it is visual and has a range of reasoning processes [10]. Conceptual graphs can be used in many computer science areas, including text analysis, web semantics, and intelligent systems [11].

A simple conceptual graph is a finite, connected, directed, bipartite graph consisting of concept nodes (denoted as boxes), which are connected to conceptual relation nodes (denoted as circles). In the alternative linear notation, concept nodes are written within []-brackets while conceptual relation nodes are denoted within ()-brackets. The concepts set and the relations set are disjoint.

A concept is composed of a type and a marker $[<$ type $>$ : $<$ marker $>$ ], for example [Disease: Idiopathic Parkinson's disease]. The type of concept represents the occurrence of object class. They are grouped in a hierarchical structure called a concepts lattice showing their inherit relationships. The marker specifies the meaning of a concept by specifying an occurrence of the type of concept.

A conceptual relation binds two or more concepts according to the following diagram:

$$
\begin{gathered}
\left.\left[\mathrm{C}_{1}\right] \leftarrow \text { (relation's name }\right) \leftarrow\left[\mathrm{C}_{2}\right]\left(\text { meaning that }{ }^{\prime \prime} \mathrm{C}_{1} \text { is related to } \mathrm{C}_{2}\right. \\
\text { by this specific relation" })
\end{gathered}
$$

In the analysis of telemedicine management, the most common relations are dependency relations, specifically, causal, conditional, temporal, and Boolean connectives, such as AND, alternating-OR and exclusive-OR relations. An example of conceptual graph is shown in Fig. 1: a medical activity is the agent of a telemedicine service and its duration is influenced by the diagnostic criteria. The semantics of the core and extended CGs is defined by a formal mapping to and from a common abstract syntax and model-theoretic foundation for a family of logic-based notations (ISO/IEC 24707) [12].

A derivation is a finite sequence of these elementary operations that have a formal semantics based on a logical interpretation. As a result, the meaning of graph operations is determined in light of the derivation to be applied, based on a logical interpretation which gives full effect to the visual reasoning [13]. The derivation has one of three conceivable properties on the logical relationship between a starting graph $u$ and the resulting graph $v$ [14]:

\subsubsection{Equivalence}

Copy and simplify are equivalence rules, which generate a graph $v$ that is logically equivalent to the original: the knowledge of $u$ is included in $v$ and the knowledge of $v$ is included in $u$ (logical meaning $u \subset v$ and $v \subset u$ ).

\subsubsection{Specialization}

Join and restrict are specialization rules, which generate a graph $v$ that implies the original: $v$ contains more specific knowledge than $\mathrm{u}$ (logical meaning $v \subset u$ ).

\subsubsection{Generalization}

Detach and unrestrict are generalization rules, which generate a graph $\mathrm{v}$ that is implied by the original: $v$ contains less precise knowledge than $v$ (logical meaning $u \subset v$ ).

Ontological knowledge provides a formal description of the studied system [15] with associated experiences and lessons learned [16,17].

\subsection{Exploitation of conceptual graphs representation in reasoning}

A formal knowledge modelled by CGs in experience feedback processes can be a very useful tool for conveying accurate meaning to a collaborative work environment involving domain experts [18]. For a given application, several viewpoints of expertise may be engaged in combination. For example, some investigations to improve the availability of a geriatric health care system can involve expert knowledge in tele-expertise and associated remote practices.

During the knowledge modelling phase of the telemedicine rules, the use of CG properties will help to enrich the telemedicine knowledge base in order to ease their access, sharing and reuse by the members of the telemedicine management in their individual and collective tasks. Furthermore, experience gained and lessons learned from initial problem solving developments will be applied as soon as possible in similar situations in other collaborative telemedicine activities with temporal modelling considerations [19].

In conceptual structures, the operations of visual reasoning with semantic mapping form the bridge from perception to different forms of conceptual operations, ranging from specialization and generalization to unification [20]. When the conceptual graphs operations are used in the visual reasoning, semantic comparisons are deployed at every step, and the only difference between deduction and analogies is the nature of the orientations on the reasoning [21]. Particularly, one conceptual graph is similar to another if there is a semantic mapping (graph homomorphism) from the first graph to the second one. In this context, the casebased reasoning can be engaged to search some unknown features of a new case from its known features and previous cases stored in the cases base. In analogical reasoning, the conceptual structure that describes known features of the new case is compared with the matching features of the conceptual structures associated to previous cases [22]. The assessment takes into account the determined degree of similarity and classified alternative options for other cases. The case that provides the greatest correspondence 


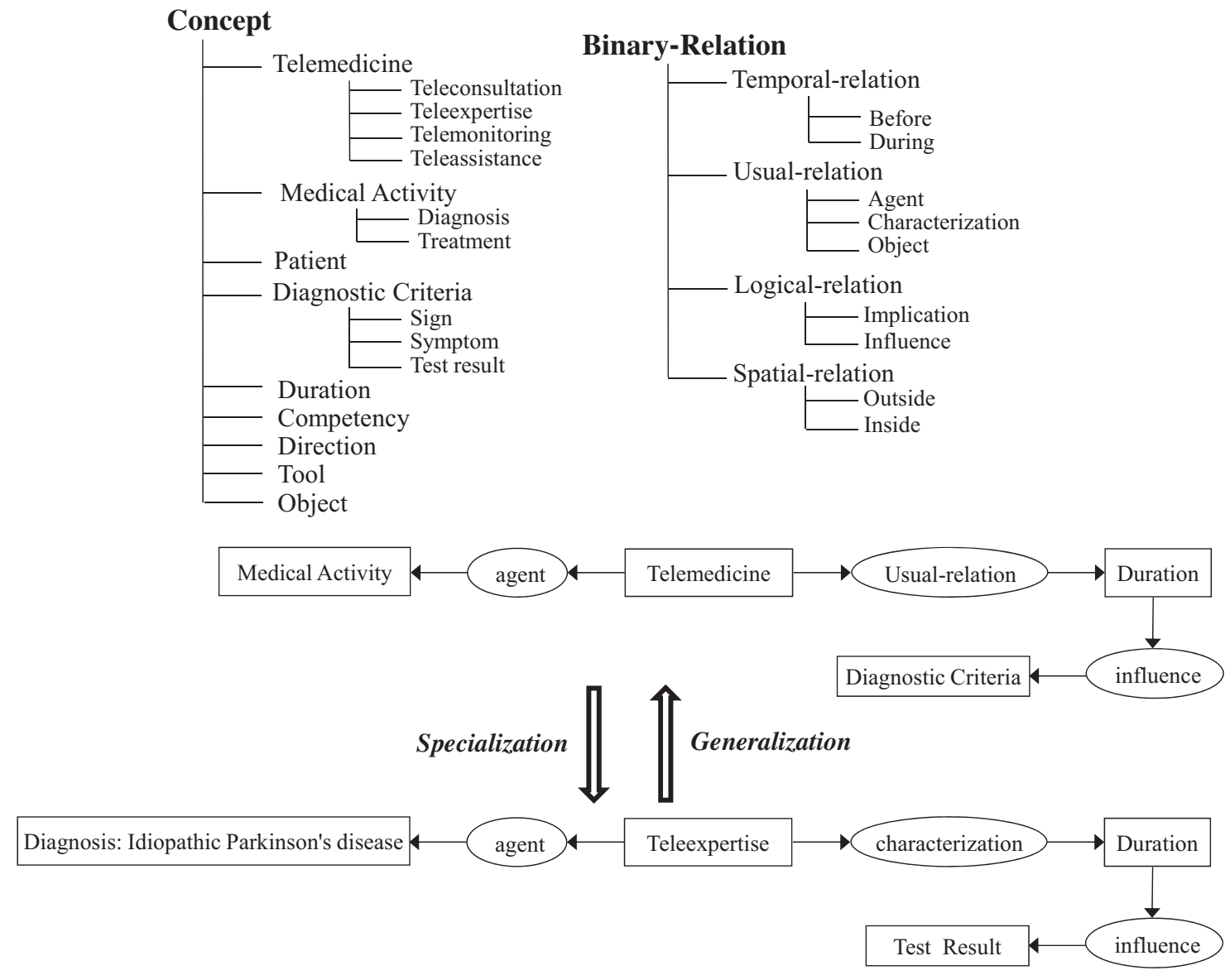

Fig. 1. Examples of concepts/relations hierarchies and conceptual graph.

may be undertaken as the top basis of indication for approximating the unknown features of the new case.

\section{Results}

We illustrate the proposed approach using CGs with the case study of synucleinopathies mostly neurologic or geriatric diseases. The accommodation of the aging population is a major concern in health care and for families [23]. The cost of medical interventions for the elderly, who are often frail and with recurring episodes of chronic diseases, is increasing [24]. Support for these vulnerable people, who are often isolated, requires the deployment of flexible and effective systems to prevent hospitalizations sometimes experienced by elderly as a traumatic event and enable the elderly to maintain their living place if possible [25]. Could new technologies provide some solutions? The expected benefits are summarized by economic gain or improvement in the care of elderly patients or their quality of life. Also are health care teams they ready to embrace these new technologies?

\subsection{Clinical outline of the synucleinopathies}

This application is in the context of decision support in health and relates particularly to neuroscience and especially synucleinopathies, a group of neurodegenerative diseases characterized by fibrillary aggregates of alpha-synuclein protein (the major components of Lewy bodies, dystrophic (Lewy) neuritis, and the Papp-Lantos filaments) in the cytoplasm of selective populations of neurons and glia. These disorders include mainly Parkinson's disease (PD), dementia with Lewy bodies (DLB), multiple system atrophy (MSA), and also pure autonomic failure (PAF) and Hallervorden-Spatz syndrome (HHS) [26]. Clinically, they are characterized by a chronic and progressive decline in motor (mainly Parkinsonism), cognitive, behavioral, and autonomic functions, depending on the distribution of the lesions [27]. Although there are validated clinical and pathological consensus criteria for PD, DLB, and MSA, because of clinical overlap, differential diagnosis is sometimes very difficult [28]. Moreover, early diagnosis of these diseases is also difficult [29]. Several approaches and new biomarkers are being investigated to facilitate the early ante-mortem diagnosis, as the common hallmark of synucleinopathies is the finding of alpha-synuclein protein on brain biopsy. Among these potential new biomarkers, there are myocardial metaiodobenzyl guanidine (MIBG) scintigraphy [30], functional cerebral imageries (reduced dopamine transporter activity in some part of the brain), olfaction's tests threshold revealing hyposmia and olfactory pathway pathology [31]. Others new diagnosis core features as Rapid Eye Movement sleep (REM sleep), behavior disorder, severe neuroleptic sensitivity, some clinical signs, symptoms and biological elements are assessing the structure of these features against the criteria set out in the guideline. However, there diagnosis accuracy is not optimal, but in most of cases, they contribute to eliminate differential diagnosis. It will be useful to investigated news approaches adapted to these new needs with possibility to improve diagnosis criteria.

In Parkinson's disease (PD) for example, non-motor symptoms are (described in Table 1): olfactory dysfunction, depression, constipation, pain, genitourinary problems, sleep disorders, and cognitive impairments. These are often long ignored, and are common [32]. They sometimes precede motor symptoms and should be thoroughly investigated because they lead to a 
Table 1

Description of non-motor symptoms associated with Idiopathic Parkinson's disease adapted from [42].

\begin{tabular}{|c|c|c|}
\hline \multicolumn{2}{|c|}{ Non-motor symptoms associated to Idiopathic Parkinson's disease } & \multirow{2}{*}{$\begin{array}{l}\text { Supposed brain damage } \\
\text { Locus coeruleus (norepinephrine), inferior raphe } \\
\text { nucleus (serotonin), amygdala }\end{array}$} \\
\hline $\begin{array}{l}\text { Psychological, psychiatric and } \\
\text { cognitive symptoms }\end{array}$ & Depression, anxiety, panic attacks, feeling hopeless & \\
\hline & $\begin{array}{l}\text { Apathy, anhedonia, inattention, vegetative symptoms of } \\
\text { depression }\end{array}$ & Uncertain \\
\hline & $\begin{array}{l}\text { Psychosis, inappropriate behavior and other adverse behavioral } \\
\text { effects disorders, obsessive-compulsive disorders, delirium }\end{array}$ & Limbic cortex, amygdala \\
\hline & $\begin{array}{l}\text { Parkinsonism dementia, confusion, hallucinations (iatrogenic } \\
\text { factor) }\end{array}$ & $\begin{array}{l}\text { Temporal lobe, hippocampus, locus coeruleus, } \\
\text { amygdala, nucleus basalis of Meynert (acetylcholine) }\end{array}$ \\
\hline \multirow[t]{2}{*}{ Sleep disturbances } & $\begin{array}{l}\text { Sleep-onset insomnia, true insomnia, night time hallucinations, } \\
\text { rapid eye movement sleep behavior disorder, daytime } \\
\text { sleepiness, sleep attacks }\end{array}$ & $\begin{array}{l}\text { Subcortical nucleus (pedunculopontine and } \\
\text { subcoerulus nucleus), hypothalamus }\end{array}$ \\
\hline & $\begin{array}{l}\text { Sleep fragmentation, sleep apnea (central (CSA), obstructive } \\
\text { (OSA), and complex or mixed sleep apnea), restless legs } \\
\text { syndrome (RLS) }\end{array}$ & Uncertain \\
\hline \multirow[t]{2}{*}{ Dysautonomic symptoms } & $\begin{array}{l}\text { Bladder-sphincter dysfunctions (urinary frequency and urinary } \\
\text { incontinence, dysuria), excessive perspiration, abnormal sexual } \\
\text { behavior (impotence, hypersexuality), xeropthalmia }\end{array}$ & Dorsal nucleus of vagus nerve \\
\hline & Orthostatic hypotension, post-prandial hypotension & $\begin{array}{l}\text { Vagus nerve, stellate ganglion (or cervicothoracic } \\
\text { ganglion or inferior cervical ganglion) }\end{array}$ \\
\hline Gastrointestinal symptoms & $\begin{array}{l}\text { Drooling, ageusia (taste loss), swallowing disorders, dysphagia, } \\
\text { gastroesophageal reflux, vomiting, nausea, constipation, fecal } \\
\text { incontinence }\end{array}$ & Dorsal nucleus of vagus nerve (adrenaline) \\
\hline \multirow[t]{2}{*}{ Sensory symptoms } & Olfactory disturbance & Olfactory bulb \\
\hline & Pain, paresthesias & Uncertain \\
\hline Others & $\begin{array}{l}\text { Fatigue, seborrhea (skin and greasy hair), excessive } \\
\text { perspiration, weight gain, weight loss }\end{array}$ & Uncertain \\
\hline
\end{tabular}

significant burden on the quality of life and have a significant contribution to the morbidity or mortality rates of PD. Besides, functional imaging using dopaminergic tracers with either Positron Emission Tomography (PET) or Single Positron Emission Tomography (SPECT) can identify dopamine deficiencies but may not reliably differentiate between Parkinson's disease and other akinetic rigid disorders. In addition, even a pathological examination cannot classify clinical syndromes with certainty. Despite the diagnostic criteria, a diagnosis of certainty is often difficult to establish because it requires a formal demonstration of the characteristic features of the presumptive disease. Clinicopathological studies have shown that the accuracy of a clinical diagnosis of PD is less than $80 \%$. More selected diagnostic criteria would increase the proportion of true PD cases identified to more than $90 \%$ [33].

Misdiagnosis of a synucleinopathy as another one is therefore potentially extremely dangerous for these patients because of the therapeutics implications. For example, in patients with PD or with dementia with Lewy bodies (DLB), typical neuroleptic or antipsychotic drugs could lead to neuroleptic malignant syndrome (NMS), a life-threatening neurological disorder most often due to adverse reactions of these drugs. NMS typically consists of muscle rigidity, fever, autonomic instability, and cognitive changes such as delirium, and is associated with elevated plasma creatine phosphokinase.

More recent studies advocate that language, especially semantics, may be an area of cognition capable of distinguishing earlyonset synucleinopathy patients from healthy controls and discriminating between various types of synucleinopathies [34]. Particularly, language disturbances in dementia have been factually attributed to the degradation of stored knowledge, whereas it is frequently assumed that language deficits in stroke aphasia mirror modality-specific impairment of access to intact conceptual knowledge [35]. These deficits can be an acquired disorder of language comprehension, production, and/or symbolic knowledge. In addition to memory and language impairments, assessment in other cognitive domains can also highlight the influence of semantic knowledge, for instance, on decoding the physico-chemical properties of an odorant [36]. Understanding the semantics of cognitive impairments in synucleinopathies is thus essential for a number of arguments. Identifying similarities and differences between synucleinopathies is the first step in evolving tests that are differentially sensitive to the distinct conditions, thus providing appropriate screening tests to support clinical diagnosis. Understanding the quality of impairments also provides significant information for patients and carers, helping physicians to elaborate better coping skills and care strategies. Besides, comparing the properties of cognitive impairment between patient groups had often contributed to an improvement in a semantic analysis of the process underlying executive control for understanding the normal organization of cognitive functions [33].

\subsection{Visual modelling of analysis procedures in synucleinopathies}

We can think about the contribution of artificial intelligence tools as a means of analysis to support medical tests for the early diagnosis and differentiation of these pathologies. Particularly in this context, operations of conceptual graphs can be crucial to reasoning on knowledge with visual explanations. This knowledge can provide evidence and analysis relevant to the activities of diagnoses and it is very important for medical research in geriatrics or neurosciences. To that end, we plan to include the engagement of reasoning techniques to determine by sequential association rules [37] the most significant rules to assist in the establishment of the most appropriate diagnosis and to eliminate differential diagnoses. Shared practice rules face the challenge of creating a solid foundation to support the cognitive development of collective intelligence. These rules can be annotated using domain ontologies and evaluated by other users, who might consider a form of suggestion using intelligent components based on the annotations associated with a synucleinopathy. For example, given a collaborative action on a synucleinopathy, decisions regarding 
this action can be automatically suggested based on the annotations, providing the most effective decisions semantically related to this action. In addition, an adaptation rule is a form of experiential learning [38], insofar as it is studied in terms of how to respond to a mismatch between the expected situation and the results observed. This leads to a learning semantic requiring a different type of conceptual organization consistent with a higher level of abstraction to obtain a better understanding of the effects on the rules and knowledge manipulated.

We consider now the conceptual graph describing the collaborative expertise (as shown in Fig. 2). In this graph, the different specialists can apply appropriate strategies to identify, localize, and (where possible) correct the errors in the knowledge modelling. The conceptual graph specifies the use of intelligent analysis strategies to narrow down and pinpoint medical disorders. Through the medical knowledge base, such crucial expert descriptions can be shared and reused by the specialists in their individual and collective tasks. As a result, by means of the disorders strategies, from which specialists learn, they are able to transfer the acquired knowledge and lessons learned easily to another similar context, with the goal of preventing disease consequences or reducing them to a minimum. They will be able to determine whether a context is problematic, whether the diagnosis or information flow is incorrect, or if the analysis of the disease context is defective.

We can also use this experienced knowledge for dedicated analysis of the specific studied disease (e.g., Parkinson's disease in Fig. 3). Thus, in order to assess, interpret, and verify the reasonableness of the modeled knowledge, one would have to ensure that the various types of targeted situations are consistent by using the projection operation of CGs. Furthermore, the analysis should not be viewed as the problem of one expertise more than another but as a global problem, which all involved members of the collaborative organization would address.

We put forward an ontological model and conceptual structure loosely based on the visual approach used to support team based telemedicine collaboration. In the considered medical context, healthcare involves a variety of specialized experts in different fields who are often geographically separated. They appreciate collaborative actions to fix a particular complex problem for which their background and training make them qualified. In this case study, telemedicine actually helps in the diagnostic decision process, since it yields improvement in terms of the cost and/or time needed to arrive at a decision. Research and progress on telemedicine could be valuable; especially we are actually testing it in a real telemedicine environment.

\section{Discussion}

The mainstream eHealth interoperability enhancement efforts in the EC and key standards development organizations are roughly classified into: legal interoperability, organizational interoperability, technical interoperability, and semantic interoperability. While paper objectives target challenges of semantic interoperability, the discussions therein also provide heavy coverage on issues of technical interoperability (on telemedicine infrastructure) and to some extent on organization interoperability. Furthermore, there are ongoing activities to develop and/ or harmonize eHealth interoperability standards (led by the likes of Continua Health Alliance, IHE, IEEE/ISO, ITU eHSCG, IHTSDO, etc.). There is a need for further research regarding organizational change, incentives, liability issues, end-users HIT competences and skills, structure and work process issues involved in realizing the benefits from health information technologies (HIT) [39].

Under the coordination of the health information systems strategy delegation, a working group of the French National Steering Committee of Telemedicine has developed a series of concrete recommendations for the operational implementation of technical systems underlying the telemedicine projects and activities [40]:

- to promote the implementation of a comprehensive and coherent infrastructure to include the implementation of telemedicine projects in a coherent urbanization;

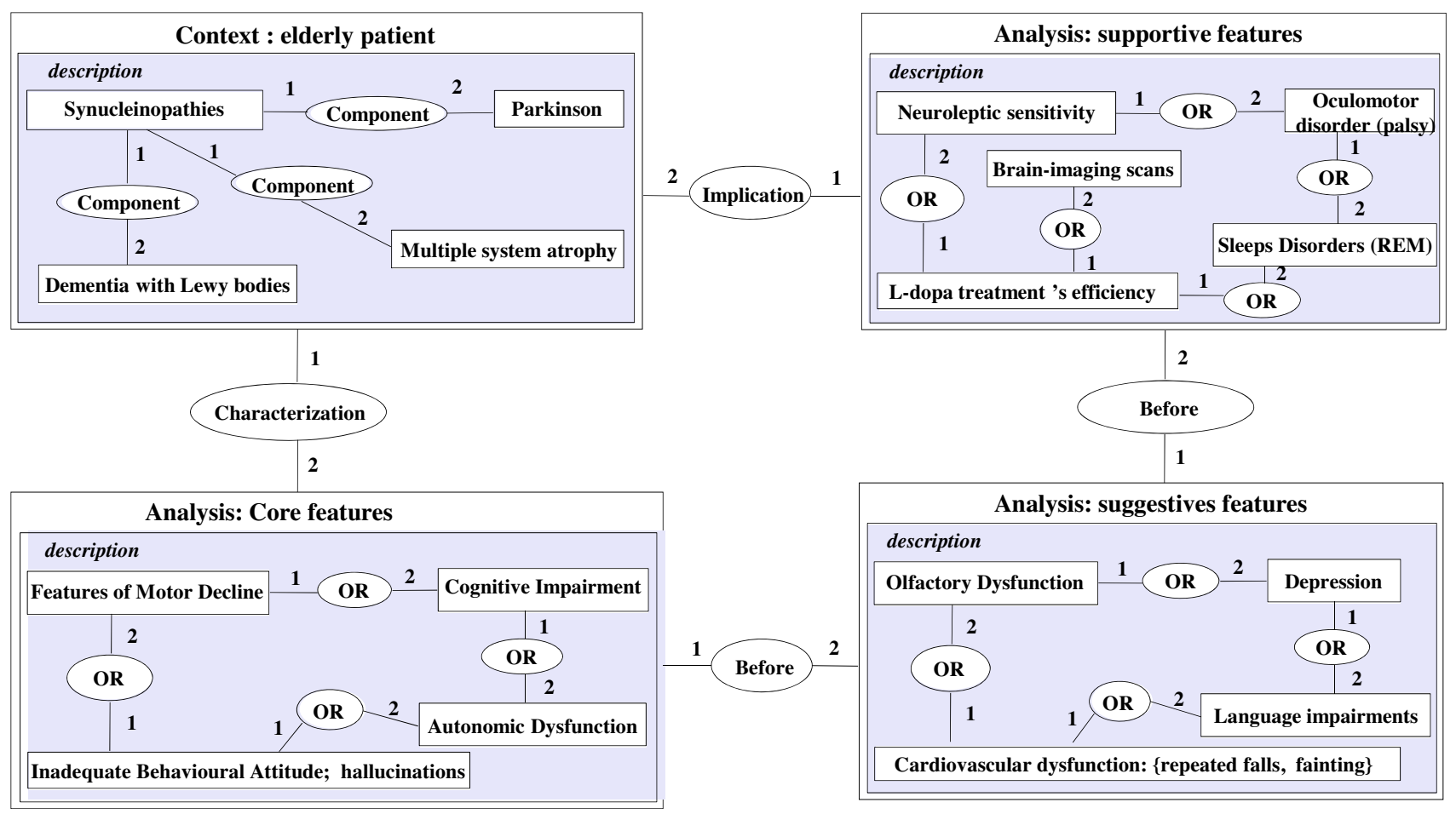

Fig. 2. A conceptual graph for knowledge modelling in synucleinopathies. 


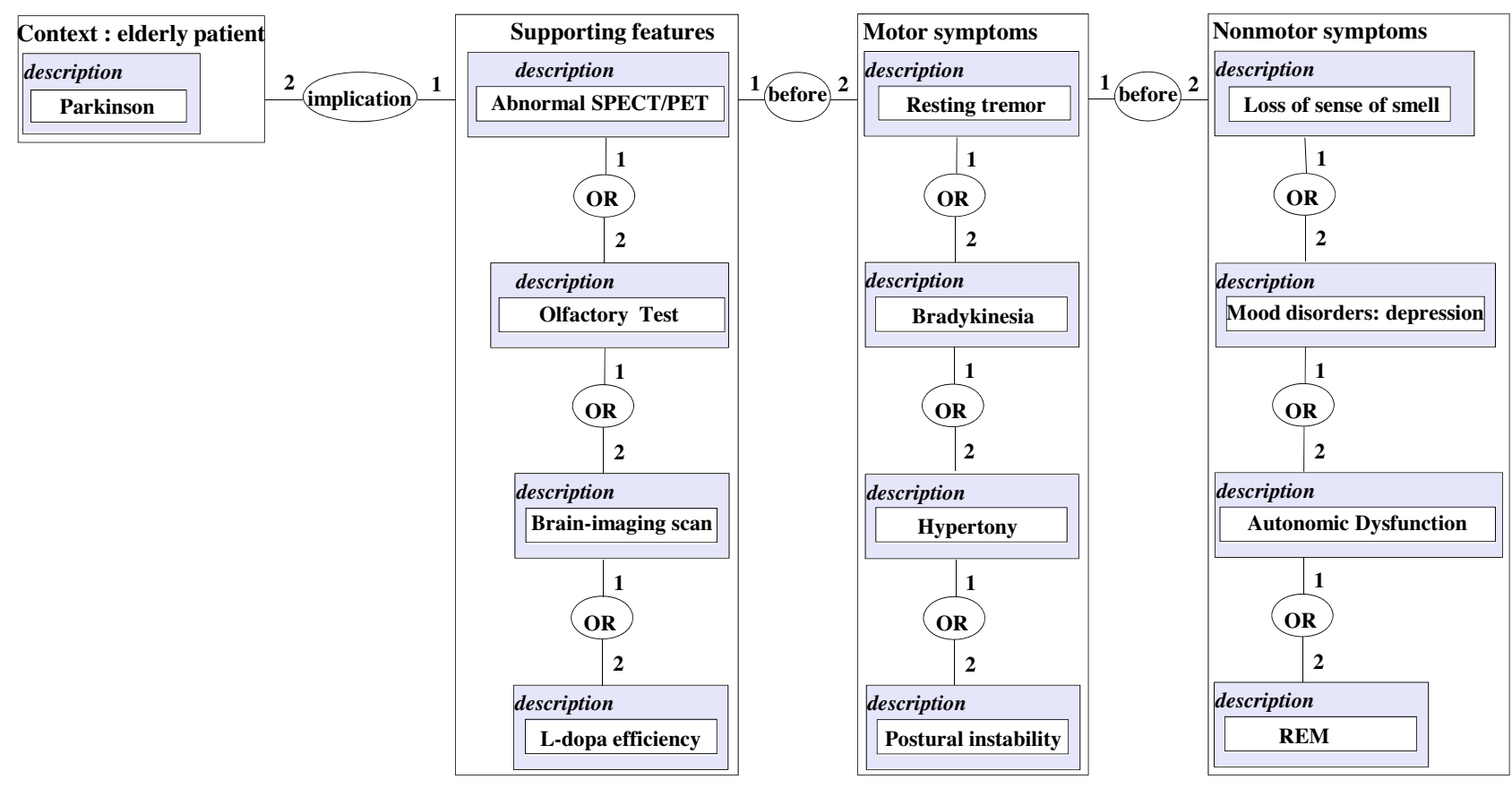

Fig. 3. A conceptual graph for knowledge modelling in Parkinson's disease.

- to conduct a risk assessment relating to the security of information systems that may affect the successful accomplishment of the activity concerned;

- to develop a global and consistent management of the technical devices to ensure that their diversity really is enriching;

- to provide training, suitable support and an adapted assistance: supervised study periods and tutoring services;

- to establish a conventional setting corresponding to the contracts for the provision of updated technical services in conducting ongoing dialogue with technological third parties.

In practice, this mainly means the capacity to ensure an effective management of personal data, while ensuring compliance with data protection principles and security of data exchanges between different organizations that are concerned by the telemedicine procedures. Secondly, it is important to prevent risks threatening the safety of operational devices. To do this, operators need to carefully and constantly apply effective methodologies and further advances in exploration and development techniques to increase the likelihood of detecting a hazard affecting the safety of considered devices. Some events may cause undesired operation (namely service interruption, fraudulent interference on the part of a third party or computer viruses or inappropriate timing of tasks and impaired signals or data) and we should monitor the significant operational risks of the implement of the telemedicine procedures, in order, inter alia, to identify at an early stage unforeseen adverse effects and to have a look at possible solutions (palliative, curative and preventive options).

Furthermore, it is important to improve as far as possible case management at all components of the proposed implementation of the technical aspects of telemedicine devices in a global framework based on formal procedures and founded on best practices. In this context, it would ensure a sufficient level of comprehension, accession and assimilation by the medical actors and health professionals using telemedicine devices for the full registration of the remote services in the everyday professional practices. Therefore, it is essential to establish with technological third parties, in the framework partnership agreements signed between them and the Project Manager, requirement levels consistent with the needs identified in the agreements with business stakeholders.

\section{Conclusion}

In this paper, we have shown that the use of knowledge modelling and formal semantic techniques provide additional support to telemedicine tasks by improving the user understanding of the diseases being treated. We made a case study with the knowledge modelling of synucleinopathies in elderly. The results of this study gave rise to a series of recommendations, which in turn will form the foundation of the collaborative action plan in response to telemedicine management. Particularly, non-motor symptoms play an essential part in appropriate diagnosis of synucleinopathies and a very insightful and knowledgeable analysis of their systemic temporal development schemes should more consequently be taken into consideration within the elaboration of diagnostic programmes in the field of health policy. However, while the motor-based disease (or even cognitive disorder) diagnosis system is described in some detail, the elements of the considered non-motor symptoms evaluation are sketchy, in particular with regard to process and management. Such facilities are currently an early stage and for instance, olfactory tests, which were supposed to be automated, had to be executed manually in order to ensure correctness of processing and reports on diagnostic evaluations. As well, these processes often are held over a couple of hours, requiring time investments from patients and health professionals. This does not allow the medical actors responsible for the regular outpatient consultations to validate some medical investigations and diagnosis for acute illness and preventive health care. We will achieve these investigations through the close collaboration of ambulatory care with interested physicians and medical reference centers. It is currently associated with a movement to include a focus on the health of elderly persons to help to verify that equality in access to health care is made a reality. Under collaborative activities made in telemedicine, medical organizations are pooling their resources and structures to implement a sustainable and effective inclusion 
programme designed to guarantee maximum possible coverage and equal conditions as regards access and treatment for patients, regardless of their age or place of residence.

Relying on the modelling of expert knowledge through conceptual graphs operations, we proposed an approach that positively impacts the telemedicine management plans:

- a better access to available best practices and methodologies as well as support training and the exchange of information on new practical developments related to critical medical activities.

- a framework of practical knowledge and good practice to ensure modelling of needed information, quality tutoring and to bring stakeholders together at organization and global levels.

- a possible conceptual modelling with reasoning mechanisms for the analysis and exchange of good practices on access to services. To that end, good modelling practice on access to traces of reasoning should be promoted.

If the significant potentials of telemedicine to assist in the management guidance and outpatient care are to be realized, then research strategies need to be undertaken to improve disease diagnosis and monitoring. However, the modalities of such an approach should be clarified so as to allow greater security, flexibility and ergonomic functionalities [41] in responding to the pragmatic needs of medical procedures [42] and efficient use of experienced health care providers [43-51].

\section{Disclosure of interest}

The authors declare that they have no conflicts of interest concerning this article.

\section{References}

[1] Simon P, Williatte Pellitteri L. Le décret français de télémédecine : une garantie pour les médecins. Eur Res Telemed 2012;1(2):70-5.

[2] van den Berg N, Schumann M, Kraft K, Hoffmann W. Telemedicine and telecare for older patients-A systematic review. Maturitas 2012;73(2):94-114.

[3] Ekeland AG, Bowes A, Flottorp S. Effectiveness of telemedicine: a systematic review of reviews. Int J Med Inform 2010;79(11):736-71.

[4] Adewale D, Olumide Sunday Adewale. An internet-based telemedicine system in Nigeria. Int J Inf Manage 2004;24(3):221-34.

[5] Lareng L. Telemedicine in Europe. Eur J Intern Med 2002;13(1):1-3.

[6] Bensink M, Hailey D, Wootton R. A systematic review of successes and failures in home telehealth: preliminary results. J Telemed Telecare 2006;12:8-16.

[7] Krupinski EA, Patterson T, Norman CD, Roth Y, El Nasser Z, Abdeen Z, et al. Successful models for telehealth. Otolaryngol Clin North Am 2011;44(6): 1275-88.

[8] Black R, Fava F, Mattei N, Robert V, Seal S, Verdier V. Case studies on the use of biotechnologies and on biosafety provisions in four African countries. J Biotechnol 2011;156(4):370-81.

[9] Sowa J. Conceptual structures: information processing in mind and machine. The systems programming series. Boston, Massachusetts, USA: Addison-Wesley Longman Publishing Co., Inc; 1984. p. 481.

[10] Chein M, Mugnier M-L. Graph-based knowledge representation: computational foundations of conceptual graphs. Series: advanced information and knowledge processing. London (United Kingdom): Springer; 2008 [445 p.; ISBN 978-1-84800-285-2].

[11] Hitzler P, Scharfe H. Conceptual structures in practice, 1st ed, Chapman and Hall/CRC; 2009 [425 p.; ISBN-10: 1420060627, ISBN-13: 978-1420060621].

[12] Sowa JF. Knowledge representation: logical, philosophical, and computationa foundations. Pacific Grove, California (USA): Brooks Cole Publishing Co.; 2000 [608 p.; ISBN 0-534-94965-7].

[13] Kamsu-Foguem B. Knowledge-based support in non-destructive testing for health monitoring of aircraft structures. Adv Eng Inform 2012:26(4):859-69.

[14] Sowa JF. Chapter 5: Conceptual graphs. In: van Harmelen F, Lifschitz V, Porter B, editors. Handbook of knowledge representation. Foundations of artificial intelligence, 3. Elsevier; 2008. p. 213-37.

[15] Gruber TR. Toward principles for the design of ontologies used for knowledge sharing. Int J Hum Comput Stud 1995;43(4-5):907-28.

[16] Gruber TR. Ontology of folksonomy: a mash-up of apples and oranges. Int J Semant Web Inform Syst 2007;3:1-11.

[17] Kamsu-Foguem B, Coudert T, Geneste L, Beler C. Knowledge formalization in experience feedback processes: an ontology-based approach. Comput Ind 2008;59(7):694-710.
[18] Dieng-Kuntz R, Minier D, Ruzicka M, Corby F, Corby O, Alamarguy L. Building and using a medical ontology for knowledge management and cooperative work in a health care network. Comput Biol Med 2006;36(7-8):871-92.

[19] Kamsu-Foguem B, Diallo G, Foguem C. Conceptual graph-based knowledge representation for supporting reasoning in African traditional medicine. Eng Appl Artif Intell 2013;26(4):1348-65.

[20] Baget J-F, Mugnier M-L. Extensions of simple conceptual graphs: the complexity of rules and constraints. J Artif Intell Res 2002;16:425-65.

[21] Baget J-F, Leclère M, Mugnier M-L, Salvat E. On rules with existential variables: walking the decidability line. Artif Intell 2011;175(9-10):1620-54.

[22] Sowa JF, Majumdar AK. Analogical reasoning. International Conference on Conceptual Structures in Dresden, Germany, in July 2003. In: Aldo A, Lex W, Ganter B, editors. Conceptual structures for knowledge creation and communication, LNAI 2746. Springer-Verlag; 2003. p. 16-36.

[23] Combes C, Azema J. Clustering using principal component analysis applied to autonomy-disability of elderly people. Decis Support Syst 2012. http:// dx.doi.org/10.1016/j.dss.2012.10.016 [available online 6 October 2012]

[24] Perez F, Helmer C, Dartigues JF, Auriacombe S, Tison F. A 15-year populationbased cohort study of the incidence of Parkinson's disease and dementia with Lewy bodies in an elderly French cohort. J Neurol Neurosurg Psychiatry 2010;81(7):742-6.

[25] Peng Y, Zhang Y, Wang L. Artificial intelligence in biomedical engineering and informatics: an introduction and review. Artif Intell Med 2010:48(2-3):71-3.

[26] Galpern WR, Lang AE. Interface between tauopathies and synucleinopathies: a tale of two proteins. Ann Neurol 2006;59(3):449-58. http://dx.doi.org/ 10.1002/ana.20819 [PMID 1648960].

[27] Rouch I, Thomas Anterion C, Dauphinot V, Kerleroux J, Roche F, Barthelemy JC, et al. Cognitive complaints, neuropsychological performance and affective disorders in elderly community residents. Disabil Rehabil 2008;30(23): $1794-802$.

[28] Martí MJ, Tolosa E, Campdelacreu J. Clinical overview of the synucleinopathies. Mov Disord 2003;18(Suppl. 6):S21-7.

[29] Aarsland D, Londos E, Ballard C. "Parkinson's disease dementia and dementia with Lewy bodies: different aspects of one entity". Int Psychogeriatr 2009;21(2):216-9. http://dx.doi.org/10.1017/S1041610208008612.

[30] Orimo S. Clinical and pathological study on early diagnosis of Parkinson's disease and dementia with Lewy bodies. Rinsho Shinkeigaku 2008;48(1): $11-24$.

[31] Silveira-Moriyama L, Mathias C, Mason L, Best C, Quinn NP, Lees AJ. Hyposmia in pure autonomic failure. Neurology 2009;72(19):1677-81. http://dx.doi.org/ 10.1212/WNL.0b013e3181a55fd2 [10.1212].

[32] Berendse HW, Roos DS, Raijmakers P, Doty RL. Motor and non-motor correlates of olfactory dysfunction in Parkinson's disease. J Neurol Sci 2011;310(1): 21-4.

[33] Metzler-Baddeley C. A review of cognitive impairments in dementia with Lewy bodies relative to Alzheimer's disease and Parkinson's disease with dementia. Cortex 2007;43(5):583-600.

[34] Forbes K. A multi-disciplinary approach to diagnosis and assessment in earlyonset dementia. Cortex 2005;41(1):90-5.

[35] Reilly J, Rodriguez AD, Lamy M, Neils-Strunjas J. Cognition, language, and clinical pathological features of non-Alzheimer's dementias: an overview. J Commun Disord 2010;43(5):438-52.

[36] Poncelet J, Rinck F, Ziessel A, Joussain P, Thévenet M, et al. Semantic knowledge influences prewired hedonic responses to odors. PLoS One 2010;5(11):e13878. http://dx.doi.org/10.1371/journal.pone.0013878.

[37] Kamsu-Foguem B, Rigal F, Mauget F. Mining association rules for the quality improvement of the production process. Expert Syst Appl 2013;40(4): $1034-45$.

[38] Koskinen KU. Problem absorption as an organizational learning mechanism in project-based companies: process-thinking perspective. Int J Proj Manage 2012;30:308-16.

[39] Lluch M. Healthcare professionals' organizational barriers to health information technologies-A literature review. Int J Med Inform 2011;80(12):849-62.

[40] DGOS, Technical Working Group/Information Systems, French Ministry of Employment, Labour and Health. Recommendations for the implementation of a telemedicine project. Technical deployment: urbanization and infrastructure 2012.

[41] Tiako PF. Process modelling, delegation and control in global software development. Int J Comput Appl Technol 2011;40(30).

[42] Doumbouya MB, Kamsu-Foguem B, Kenfack H, Foguem C. Telemedicine using mobile telecommunication: towards syntactic interoperability in teleexpertise. Telemat Inform 2014:31(4):648-59.

[43] Kamsu-Foguem B, Tchuenté-Foguem G, Allart L, Zennir Y, Vilhelm C, Mehdaoui $\mathrm{H}$, et al. User-centered visual analysis using a hybrid reasoning architecture for intensive care units. Decis Support Syst 2012;54(1):496-509.

[44] Kamsu-Foguem B. Systemic modeling in telemedicine. Eur Res Telemed 2014;3(2):57-65.

[45] Kamsu-Foguem B. Ontological view in telemedicine. Eur Res Telemed 2014;3(2):67-76.

[46] Kamsu-Foguem B, Tchuenté-Foguem G, Foguem C. Conceptual graph operations for formal visual reasoning in the medical domain. IRBM 2014;35(5):262-70.

[47] Kamsu-Foguem B, Tchuenté-Foguem G, Foguem C. Using conceptual graphs for clinical guidelines representation and knowledge visualization. Inform Syst Front 2014;16(4):571-89.

[48] Kamsu-Foguem B, Foguem C. Could telemedicine enhance traditional medicine practices? Eur Res Telemed 2014;3(3):117-23. 
[49] Doumbouya MB, Kamsu-Foguem B, Kenfack H, Foguem C. A framework for decision making on teleexpertise with traceability of the reasoning. IRBM 2015;36(1):40-51.

[50] Kamsu-Foguem B, Foguem C. Adverse drug reactions in some African herbal medicine: literature review and stakeholders' interview. Integrative Medicine Research 2014;3(3):126-32.

[51] Kamsu-Foguem B, Tchuenté-Foguem G, Foguem C. Verifying a medical protocol with temporal graphs: The case of a nosocomial disease. Journal of Critical Care 2014;29(4):690.e1-9.

Bernard Kamsu FoguemHe has a PhD in Computer Science and Engineering from the University of Montpellier 2 in 2004. He got the "accreditation to supervise research", abbreviated HDR from University of Toulouse in 2013. His current interests are in Knowledge Discovery and Data Mining, Knowledge Representation, Formal Visual Reasoning, Ontology-based Semantic Analysis, Knowledge Exploitation for Collaboration, Decision Support Systems and Intelligent Systems. Application domains include Continuous Improvement process and Health Information Systems. He is a reviewer for a large number of international scientific journals such as Computers in Biology and Medicine, Knowledge Management Research \& Practice, Interacting with Computers, Sensors, Engineering Applications of Artificial Intelligence and Knowledge-Based Systems. He is a member of the thematic group: e-Health of InterOP-VLab (International Virtual Laboratory for Enterprise Interoperability).

Pierre F. TiakoHe is the Director of the Center for Information Technology Research at Langston University (USA) and an assistant professor of Computer Science and Information System. He worked as a visiting professor at Oklahoma State University (OSU) before the current position. Prior to OSU, he taught computer science courses and did research at Universities of Nancy and Rennes (France), and also worked as an expert engineer at INRIA, the French national institute for research in information technology. Dr. Tiako has authored more than 50 journal and conference technical papers and coedited four proceedings volumes, resulting from services as program chair for several international conferences and workshops. He holds a $\mathrm{PhD}$ in software and information systems engineering from National Polytechnic Institute of Lorraine (France). Dr. Tiako is a senior member of IEEE and past Chairman for IEEE Oklahoma City Computer Society.
Edward MutafungwaHe is a researcher and project manager at the Department of Communications and Networking (Comnet) of the Aalto University School of Electrical Engineering. He received the B.Eng. degree in Electronic Systems Engineering and the M.Sc. degree in telecommunications and information systems both from the University of Essex, Colchester, U.K., in 1996 and 1997, respectively, and the Dr. Sc Tech. degree in Communications Engineering from the Helsinki University of Technology (TKK, now Aalto University School of Electrical Engineering), Espoo, Finland, in 2004. For over a decade, he has alternatively been a lecturer, researcher and project manager in various national (TEKES, Academy of Finland) and international (EU, Celtic) projects at Comnet, Aalto University. His research interests lie within the general fields of broadband wireless communications, optical networking, ICT for development (ICT4D) and public safety communications. In the area of telemedicine, he has been studying the use of mobile broadband technologies (small cells) for implementation of personal telehealth systems and emergency telemedicine in indoor environments.

Clovis FoguemHe is an Internal Medicine and Geriatric medical doctor and has undertaken a PhD on 'Olfaction and Elderly: study of the olfactory (CN I) and trigeminal ( $\mathrm{CN} \mathrm{V)} \mathrm{sensitivities} \mathrm{interactions} \mathrm{in} \mathrm{a} \mathrm{geriatric} \mathrm{population;} \mathrm{constants} \mathrm{and} \mathrm{pathological}$ specificities'. He is also particularly interested in neurodegenerative diseases (as Parkinson disease or Lewy Body dementia), elderly epilepsy and whether pathogenic inflammatory or autoimmune responses can contribute to these disorders in the elderly. Moreover he is also interested in medical knowledge representation and medical clinic design guidelines. For his work on 'Olfaction and Elderly', Dr C. Foguem was laureate of Health Research Award for emerging health researchers from the corporate foundation 'Groupe Pasteur Mutualité' in 2011. He is grounded in medical research applications of Information and Communications Technology. Former Faculty of Medicine's Clinical Instructor, he is now Hospital Practitioner in France. He is peerreviewer of many scientist journals among which: Clinical Interventions in Aging. Degenerative Neurological and Neuromuscular Disease; International Medical Case Reports Journal; Neuroscience and Neuroeconomics; Clinical Medicine Insights; Journal of the Pancreas; International Scholars Journals (ISJ); Cancer Therapy; Indian Journal of Critical Care Medicine and, African Journal of Environmental Science and Technology. 